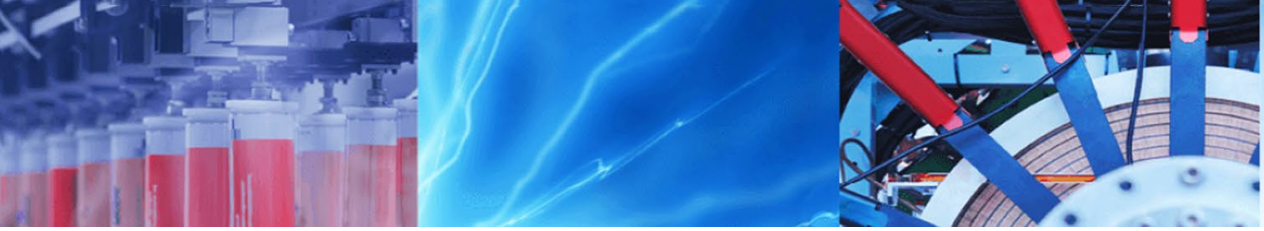

Research Article

\title{
Characteristics of experimental ductility energy index of hybrid-CFRP reinforced concrete deep beams
}

\author{
Mahir M. Hason ${ }^{1}$ (1) $\cdot$ Ammar N. Hanoon ${ }^{2} \cdot$ Sarah J. Saleem $^{3} \cdot$ Farzad Hejazi $^{3} \cdot$ Ahmed W. Al Zand $^{4}$
}

Received: 29 September 2020 / Accepted: 12 January 2021 / Published online: 25 January 2021

(C) The Author(s) 2021 OPEN

\begin{abstract}
Although the ductility energy ratio $\left(\mu_{E}\right)$ of the reinforced concrete beam has been the topic of numerous study purposes and critical inquiry for the last decades, narrow consideration, especially in terms of reinforced concrete deep beams (RCDBs), is conducted to examine the ductility energy of hybrid-RC deep beams with various CFRP configurations. Growing the ductility of RCDB by CFRP reinforcement is significant in terms of shear resistance. Therefore, the objective herein is to explore the consequence of CFRP configurations (full side warped, $45^{\circ}$ and $90^{\circ}$ side stripes) on the ductility energy of RCDBs per two values of the shear span over depth proportion $(a / d)$ of 1.0 and 1.75 , and shear reinforcement ratios $\left(\rho_{v}\right)$ of $0.0 \%$ and $0.4 \%$. The experimental testing program included 12 RCDBs, three ordinaries (unstrengthen), and nine retrofitted with several CFRP configurations. The results show that the CFRP strengthened beams is presented a higher degree of increase in terms of mid-span deflection with respect to conventional beams. The ductility energy index $\left(\mu_{E}\right)$ increases with the increase of the shear reinforcement ratio $\left(\rho_{v}\right)$. The dissipated energy demonstrated by strengthening beam with CFRP is from 45 to $80 \%$, and it was higher than those of reference RCDBs. The energy absorption of RCDBs is improved due to the attendance of CFRP configurations of about $15 \%$ and $51 \%$ for $a / d$ proportion of 1.0 and 1.75 , respectively, and for $\rho_{v}$ of $0 \%$ and $0.4 \%$ are about $15 \%$ and $86 \%$ consecutively.
\end{abstract}

Keywords Ductility energy index $\left(\mu_{E}\right) \cdot$ Deformability factor · Deep beam · CFRP · Strengthening · Failure mode

\section{Introduction}

Deep beam has constantly been a subject of great concern for the field of structural engineering. A deep beam is typically a beam that has a high ratio of depth per thickness and a ratio of shear span per depth lower than 2.5. Offshore structures, tall buildings, pile caps, and walls, and foundations often use RCDBs as a significant element in their construction [1]. The description and specification of the deep beam in terms of definition, flexural, and shear design have been detailed in the standard code [2].

Concrete spalling, cracks, big distortion, and other numerous deteriorations may affect the $\mathrm{RC}$ structures and may often collapse during their service life. These deteriorations are caused by different factors, such as steel reinforcement degradation, aging, environmental impacts, and growth loads [3]. Thus, it is significant to strengthen these structures to withstand potential high loads [3-5]. For strengthening the structural members, multiple ways are available. One of the commonly used options is a fiberreinforced polymer (FRP) for retrofitting or repair of damaged structural members $[6,7]$. Glass, carbon, or other synthetic fibers may be categorized as FRP.

Naser et al. [8] published a review article on the strengthening by FRP material. They concluded that FRP materials can be considered as a necessary component of

$\triangle$ Mahir M. Hason, mahir.mahmod@gmail.com; $\bowtie$ Ahmed W. Al Zand, ahmedzand@ukm.edu.my| ${ }^{1}$ Disaster Information Management Center, Ministry of Science and Technology, Baghdad, Iraq. ${ }^{2}$ Department of Reconstruction and Projects, University of Baghdad, Baghdad, Iraq. ${ }^{3}$ Department of Civil Engineering, Universiti Putra Malaysia, Selangor, Malaysia. ${ }^{4}$ Department of Civil Engineering, Universiti Kebangsaan Malaysia, Selangor, Malaysia. 
the latest pattern of structures according to the unique characteristics of the FRP system and their potential in improving structural element performance (i.e., torsional, shear, flexural, and axial application) relative to those composed of conventional materials. Lots of advantages have been provided to repair and/or enhance by these materials due to their high corrosion resistance, perfect fatigue behavior, excellent tensile strength to stiffness ratio, and other significant properties [9]. In general, deep beam fails in shear. Thus, when using the FRP system to strengthen such a beam, the fixed externally FRP system is primarily considered as additional web reinforcement, which plays a major or minor role against the applied shear strength.

Due to the CFRP benefit of being lightweight, installation simplicity, erosion resistance, and good tensile strength, strengthen the RC members by the likelihood of CFRP configuration has become a subject of importance among investigators, and a valuable tool for retrofitting of concrete structures element particularly beams. Externally CFRP has been effectively used for more than a decade in the field of rehabilitation of concrete structures [10]. A suggested design technique conducted by Saqan et al. [11], was built from $825 \mathrm{FRP}$ beams as a parametric study to investigate the specific scheme of FRP required for enhancing the beams. Besides, 364 beam specimens using FRP material to verify the proposed approach. They concluded that determining the needed area of FRP for a specific percent to retrofit the RC beams against flexural loads is very essential in the field of engineering.

The capability of concrete elements to maintain unyielding deformation, without loss in strength, before the collapse is called ductility [12]. Whereas, the deflection is defined as the main measurement of ductility. Exchange of mechanical energy into interior possible energy can be related to the ductility and dissipated energy of concrete components [13]. Different complicated processes may be included among the energy absorption of the concrete member. These processes involving elastic and plastic deformation, rupture mechanics of crack initiation and propagation, and notch sensitivity [14]. Generally, the deflection-load curve integral is called the energy absorption capacity [15]. Ductile elements in structure can afford multiple advantages to the structural building. The significant character of ductility is the anticipation of architectural collapse. Ductile structures can provide earlier information before the crash opposite to brittle structure members.

Ductility of the sample is required to maintain any sudden overloading situations. Although retrofitting with CFRP may increase stiffness and flexural capacity but also may decrease the ductility and capacity of the energy absorption. This conclusion has been recorded by many researchers and depended on the amount of steel reinforcement, steel fiber [16], recycled aggregate [17], the spacing of vertical reinforcement, failure mode, and CFRP strengthening orientation [18]. A study of two RCDBs enhanced with CFRP laminates and other two with steel plates were tested under impact loading for simply supported beam [19]. It was concluded that the mid-span deflection of strengthened RCDBs with steel plates was greater than a strengthened CFRP beam when exposed to the same impact loading. In other words, RCDBs enhanced with CFRP laminates for flexure behave better under impact loading, despite the energy absorption was not the same energy absorbed by beams enhanced with steel plates [19].

Another investigation was done to examine the flexural strength and performance of RC-filled fiber-reinforced polymer tube beams [20]. Four RCDBs with ordinary steel bars and six RCDB strengthened with glass FRP bars. All of the RCDBs were experimented with under four-point bending loads. The energy absorption and flexural strength conducted for beams strengthened with glass FRP bars were $7 \%$ and $9 \%$ consecutively more than the conventional steel bar beams. Furthermore, it was examined the effect of CFRP strengthening of reinforced concrete deep beams on the energy absorption with the various ratio of $a / d$ [21]. The results showed that the CFRP deep beams had a higher energy absorption potential, which is from 45 to $80 \%$, relative to conventional RCDBs.

There have been limited studies adopted on the energy absorption capacity and $\mu_{E}$-index of hybrid RCDBs enhanced with CFRP. Thus, the goal of this research is to explore the effect of different CFRP configurations on the $\mu_{E}$-index of RCDBs with different $a / d$ and $\rho_{v}$. Knowing the best orientation of the CFRP would contribute to future researches for the engineering field. Excluding the nonuseful scheme of CFRP sheets from the carried investigation manages to decrease in cost, attempts, and time. The current study is limited to conventional RCDBs, material, loading, laboratory system, and environmental condition. Besides, the limitation is also extended to the performance of the CFRP material employed to strengthen the tested RCDBs. The results displayed that there is an increase in the absorbed energy with the increase of the shear reinforcement ratio. Also, an increment in $\mu_{E}$-index with the attendance of CFRP sheets orientation.

\section{Research significant}

Although a large number of laboratory outcomes provided in the scientific historical literature concerning the confinement of RC beams by FRP, several attempts have been conducted to evaluate the effectiveness contribution of various orientation routines of CFRP laminates in improving the 
shear ductility index $\left(\mu_{E}\right)$, especially with different parameters values of $a / d$ and shear reinforcement ratios. Therefore, the current research aims to investigate the effect of a different configuration of externally bonded transverse (shear) CFRP sheets with an epoxy agent on the shear strength of the RC deep beams. The parametric study is included two amounts of shear-to-depth ratios (1\% and 1.75\%) with/without $0.4 \%$ of shear reinforcement and three schemes of CFRP sheets (full side warped, $90^{\circ}$ and $45^{\circ}$ side strips).

\section{Methodology and material}

The current study is limited to the conventional material, type of loading, laboratory system, and environmental surrounding condition. The limitation is also extended to the performance of the CFRP sheets employed to strengthen the tested RCDBs. The experimental program of this study comprised testing of three groups of RCDBs. Many expressions have been formulated to measure the ductility in terms of energy absorption for hybrid RC beams with FRP. A proposed model was suggested to compute the ductility energy ratio $\left(\mu_{E}\right)$ for hybrid FRP beams [22], as shown in Eq. 1 and Fig. 1. The energy absorption can be found by calculating the area under the curve (AUC) of the total deformation (load-deflection curve), which is calculated utilizing Simpson's rule (Eq. 2) for all beam specimens.

$\mu_{E}=\frac{E_{\text {total }}}{E_{@ 0.75 P \max }}$

where $\mu_{E}, E_{\mathrm{total}}$ and $E_{@ 0.75 P \max }$ are the ductility energy index, total energy absorption up to the failure load, and energy absorption up to $75 \%$ of the maximum load respectively.

$A=\frac{\left(P_{i}+P_{i+1}\right)}{2} \times\left(\Delta_{i+1}-\Delta_{i}\right)$

where the area under the deflection-load curve is denoted by $A$, while the applied load and the mid-span deflection

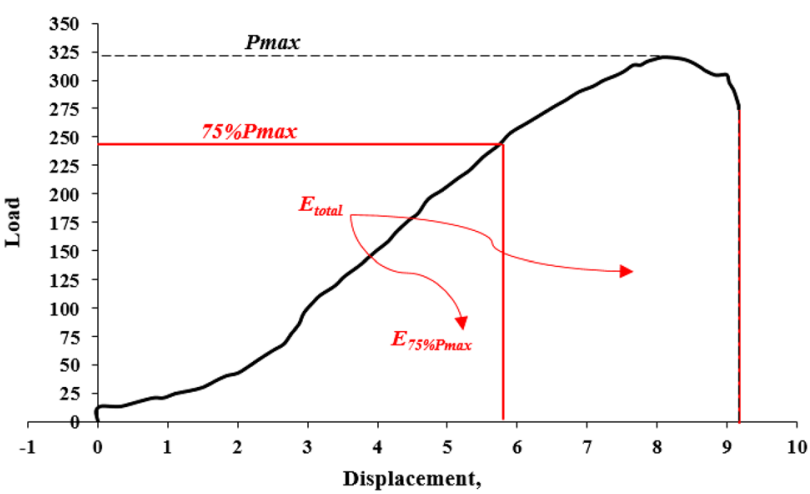

Fig. 1 Ductility energy index estimation adopted in this study of RCDBs were designated by $P_{i}$ and $\Delta_{i}$ respectively, at $i$ increment of the applied load.

The early beam settlements contained by the test apparatus may be possibly reflected by the beginning short segment of the deflection-load curve. Nevertheless, in this study, the influence of this portion of the curve on the precision of measurement of the range value beneath deflection-load curves is not the main anxiety.

\subsection{Material characteristic and samples details}

In this study, 12 RCDBs samples were tested and designed per the $\mathrm{ACl}$ code [2]. Nine of them were enhanced by CFRP sheets. The rest were conventional RCDBs. The span length of all beams was $140 \mathrm{Cm}$. The rectangular cross-section dimension was equal to $10.2 \mathrm{~cm}$ and $28 \mathrm{~cm}$ of depth and width consecutively. The ratios of 1.0 and 1.75 were the two different values of $a_{v} / d$, which utilized particularly with all tested beams. Deformed steel bars with D16 mm and D6 $\mathrm{mm}$ were set for longitudinal and shear reinforcement respectively. The ratio of flexural reinforcement was 0.033 for all beam samples. The beam designation system is displayed in Fig. 2 and Table 1. CFRP configurations and reinforcement details of RCDBs are displayed in Figs. 3 and 4 respectively.

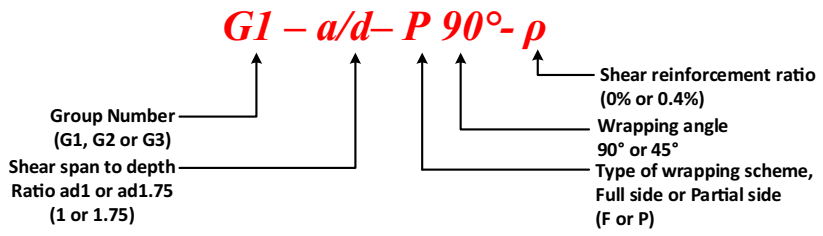

Fig. 2 Specimen designation system

Table 1 Details of specimen

\begin{tabular}{lllll}
\hline Group No. & Beam ID & $\rho_{v}(\%)$ & $(a / d)$ & CFRP \\
\hline Group 1 & $\mathrm{G} 1-a / d 1-\mathrm{R}-\rho 0$ & 0.0 & 1.00 & Reference \\
& $\mathrm{G} 1-a / d 1-\mathrm{F}-\rho 0$ & & & Full side coverage \\
& $\mathrm{G} 1-a / d 1-\mathrm{P} 90^{\circ}-\rho 0$ & & & $90^{\circ}$ slide coverage \\
& $\mathrm{G} 1-a / d 1-\mathrm{P} 45^{\circ}-\rho 0$ & & & $45^{\circ}$ slide coverage \\
Group 2 & $\mathrm{G} 2-a / d 1-\mathrm{R}-\rho 0.4$ & 0.4 & & Reference \\
& $\mathrm{G} 2-a / d 1-\mathrm{F}-\rho 0.4$ & & & Full side coverage \\
& $\mathrm{G} 2-a / d 1-\mathrm{P} 90^{\circ}-\rho 0.4$ & & & $90^{\circ}$ slide coverage \\
& $\mathrm{G} 2-a / d 1-\mathrm{P} 45^{\circ}-\rho 0.4$ & & $45^{\circ}$ slide coverage \\
Group 3 & $\mathrm{G} 3-a / d 1.75-\mathrm{R}-\rho 0.4$ & & 1.75 & Reference \\
& $\mathrm{G} 3-a / d 1.75-\mathrm{F}-\rho 0.4$ & & Full side coverage \\
& $\mathrm{G} 3-a / d 1.75-\mathrm{P} 90^{\circ}-\rho$ & & $90^{\circ}$ slide coverage \\
0.4 & & \\
$\mathrm{G} 3-a / d 1.75-\mathrm{P} 45^{\circ}-\rho$ & & $45^{\circ}$ slide coverage \\
0.4 & &
\end{tabular}


As highlighted earlier, Twelve RCDBs have been cast to use in this study. Three main groups were created from these beam specimens, Group 1, 2, and 3 and they had the notations of $\mathrm{G} 1, \mathrm{G} 2$, and $\mathrm{G} 3$ respectively. Each group included one conventional control specimen and three specimens strengthened with CFRP Sheet and they were experimented with four-point loads till collapse. G1 and G2 were tested with $\rho_{v}$ of zero and $0.4 \%$ respectively with av/d equal to 1.0 , whereas $\mathrm{G} 3$ was tested with $\rho_{v}$ and $a_{v} / d$ of $0.4 \%$ and 1.75 respectively.

For all the beams, a standard layer of concrete cover $(20 \mathrm{~mm})$ was used. an overall gravel size of $1.0 \mathrm{~cm}$. The concrete mixture was utilized to mold the samples of $41.6 \mathrm{MPa}$ compressive strength $\left(f^{\prime} c\right)$ on the test day. Concrete cylinders (diameter to height of $15 \mathrm{~cm}$ to $30 \mathrm{~cm}$ respectively) were utilized from the corresponding group of concrete mix to estimate the $f^{\prime} c$ at 28 days under the same curing regime (water submerge). The yield strength of shear and longitudinal reinforcements were conducted of $350 \mathrm{MPa}$ and $410 \mathrm{MPa}$ consecutively. The area of longitudinal reinforcement was $8.0 \mathrm{~cm}^{2}$. The maximum size of aggregate was $10 \mathrm{~mm}$, while the normal sand was utilized as fine aggregate. The concrete mixture design is illustrated in Table 2

An M-Brace/CF130 unidirectional CFRP was utilized in this research. The distribution of fibers was in one-direction for all CFRP c0nfigutation. Each sheet had a thickness of $0.166 \mathrm{~mm} / \mathrm{ply}$. The area weight of the FRP sheet was $300 \mathrm{~g} / \mathrm{m}^{2}$. It is worth mentioning that the adhesive exhibits as a connection tool and consists of a couple of main elements called hardener and resin. The durability of adhesive must be satisfactorily to resist the environmental circumstances to match the active life of the structure members. The mixing ratio of these components is 3:1 with time not exceed $30 \mathrm{~min}$ to use after mixing. The CFRP material characteristics were tested using coupon samples in direct tension by $45,000 \mathrm{~N}$ capacity examine tool according to ASTM D 3039/D $3039 \mathrm{M}-2000$. The length and width of the warping sheet were $200 \mathrm{~mm}$ and $25 \mathrm{~mm}$ respectively. The physical characteristics, provided by the manufacture and experimentally, of these materials are presented in Table 3. The CFRP-enhancing process was followed after casting the beam samples in the third week. The CFRP layer was carried out exactly on the shear span region, just between the support and applied load, of the concrete surface to the RCDBs. Two days were the cured time reported by the manufacturer for the CFRP reinforcing.

\subsection{Test procedure and instrument}

Samples were examined in the MTS universal testing machine with a compression capacity of $1000 \mathrm{kN}$. The total numbers of examined RC samples were 12 deep beams subjected to a third-point loading mechanism before failure. Before testing, all RCDBs were cleaned and coated on both sides with white paint to observe the cracking throughout the experimentation. A rigid beam was employed to apply double point loads above the tested RCDBs. To gauge the required loads and deflections, all apparatuses, devices, and tools, including strain gauges and load cells, were associated with tested beams. The mid-span settlement of the beam was calculated by using LVDTs supported underneath the base surface of the beam. The diagram of the tested RCDBs is plotted in Fig. 5 .

\section{Results and discussion}

\subsection{Failure modes}

Over the past two decades, Researchers have been interestingly studied the mode of shear failure and crack width of RC beams. Shear failure for RCDBs is generally more dangerous than flexural failure. Failure modes can be categorized into five expected types: Steel bars yielding, concrete crushing in compression, shear reinforcement failure without CFRP rupture, CFRP layer rupture, and depending [23]. CFRP layer may control the shear failure mode according to layer thickness, number of CFRP sheets, and strengthening approaches. it has been distinguished that once the inclined cracking begins to separate in the RCDBs during the mode of failure, the incorporation between shear reinforcement and RCDB acts as a truss.

The consideration of studying the failure mode of conventional and CFRP-enhanced RCDBs is taken. Experimentally, an increase in brittle failure was clearly observed for the conventional tested RCDBs as the $a_{v} / d$ ratio reduced. Conversely, RCDBs enhanced with CFRP displayed a slightly better propensity in terms of fragile failure compared to non-enhanced RCDBs. In this experiment, the failure mode caused by steel reinforcement yielding was not observed.

Concerning unstrengthen RCDBs, the failure mode of concrete at the support and loading zones was detected. The appropriate amount of longitudinal steel reinforcement was provided to avoid the steel bars from yielding mode. Moreover, the style of the collapse of the end anchorage was not observed because the edge of the main steel reinforcement was fused with an iron base of $1 \mathrm{~cm}$. The shear failure with inclined cracks spreading toward the support and load controlled for conventional RCDBs as revealed in Fig. 6 from this experiment, similar to prior research findings.

It is well documented by Naser et al. (2019) that one of the primary disadvantages of CFRP sheets is the truth that CFRP laminate might debond from the 


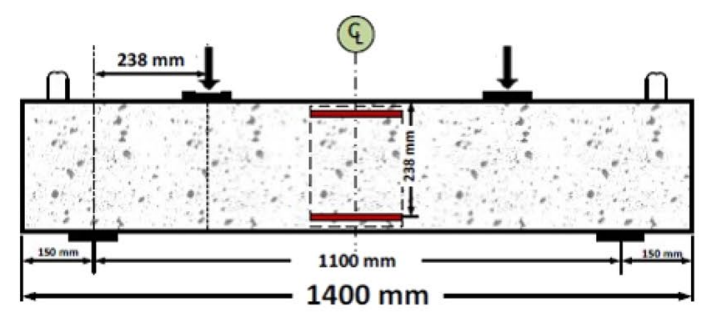

$\mathrm{G} 1-a / d 1-\mathrm{R}-\mathrm{p} 0$
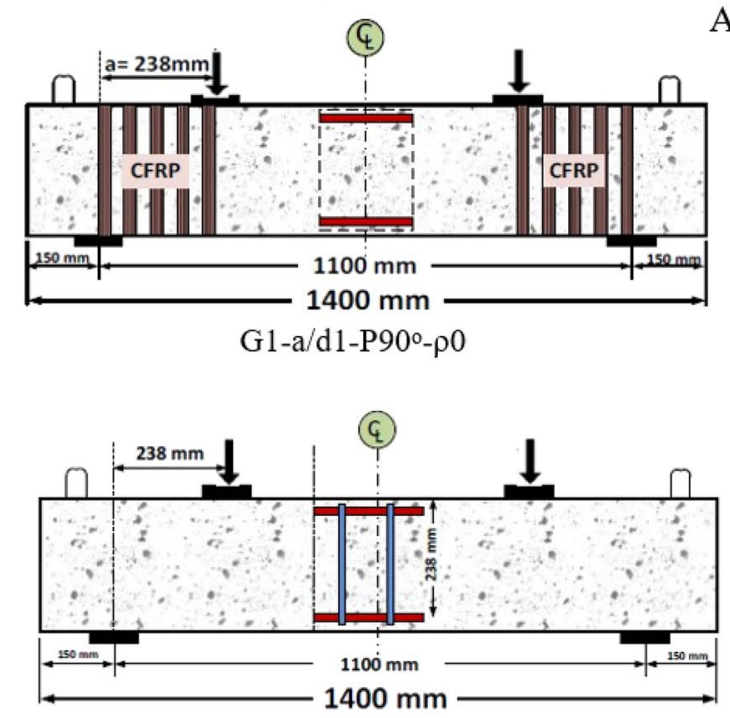

$\mathrm{G} 2-\mathrm{a} / \mathrm{d} 1-\mathrm{R}-\mathrm{\rho} 0.4$

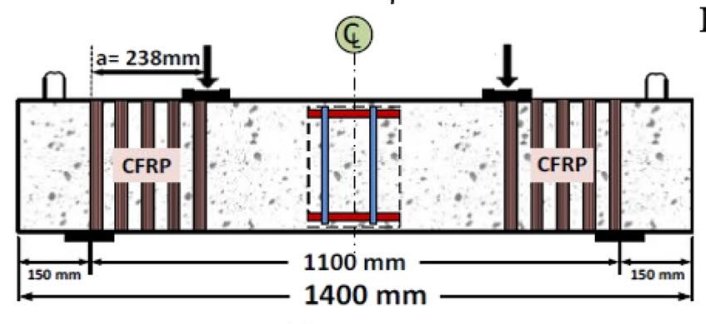

G2-a/d1-P90º-p0.4

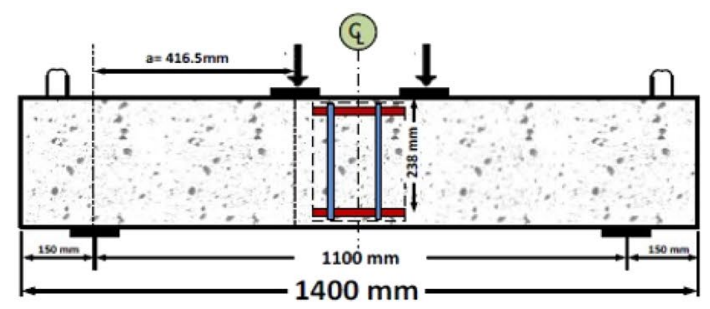

G3-a/d1.75-R-p0.4

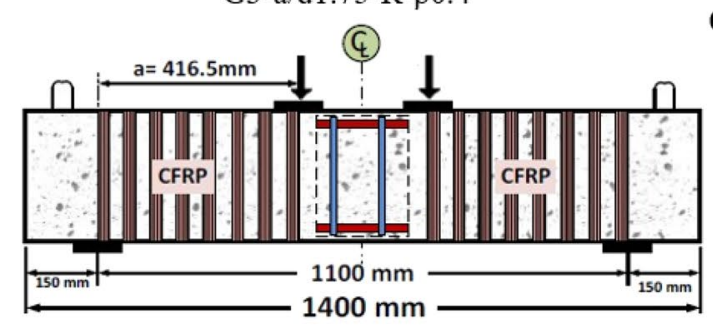

G3-a/d1.75-P90º-p0.4

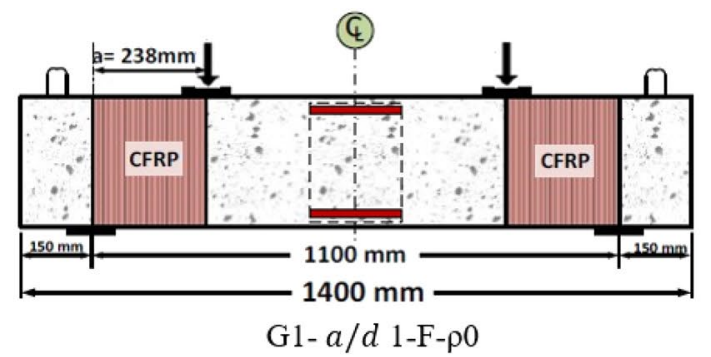

A
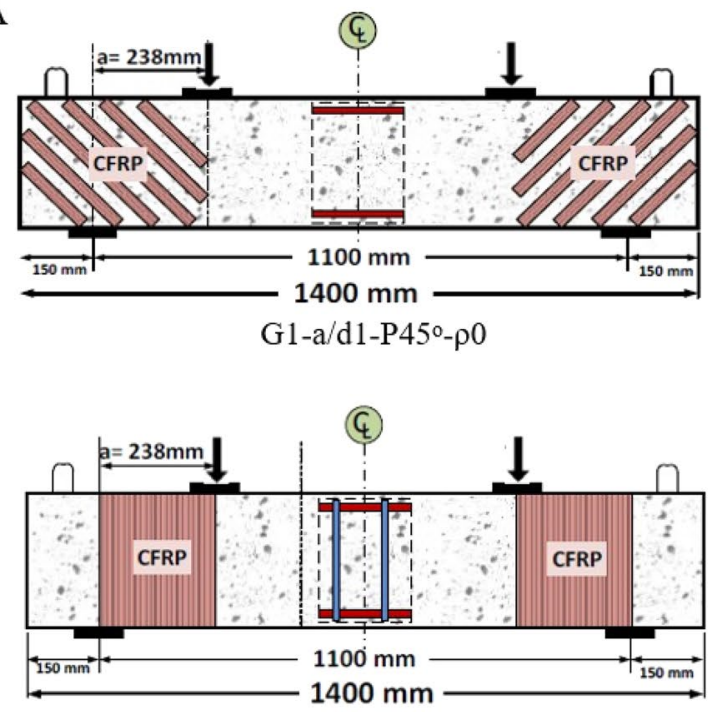

G2-a/d1-F-p0.4

B
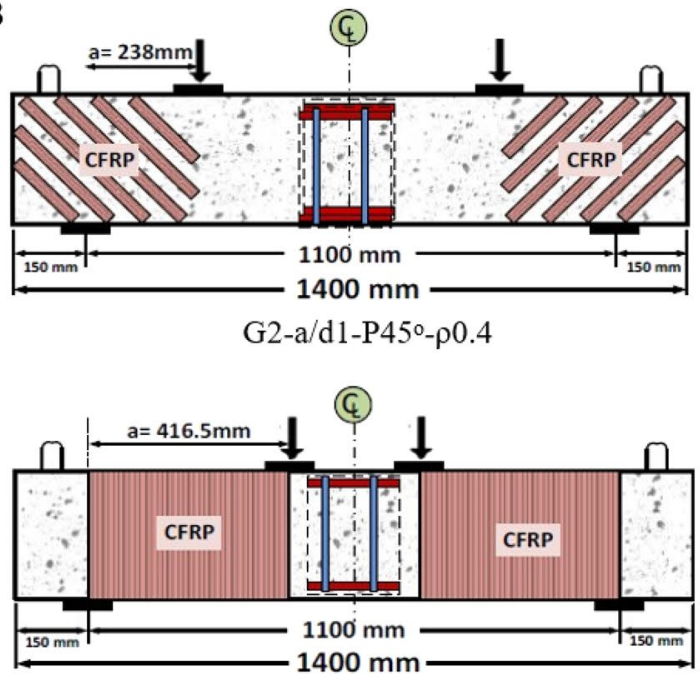

G3-a/d1.75-F-p0.4

C

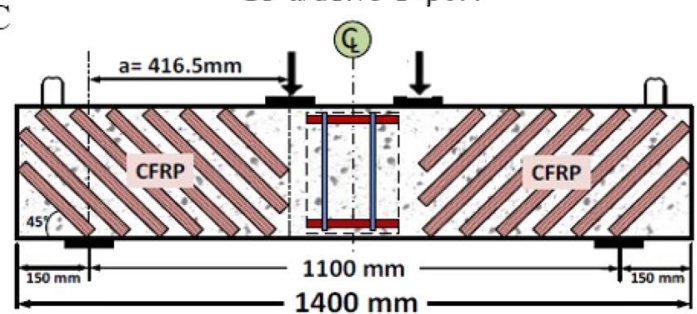

G3-a/d1.75-P45ㅇ-p0.4

Fig. 3 Typical dimensions, reinforcements, and CFRP configurations of RCDBs a Group 1, b group 2, c Group 3 
Fig. 4 Cross section of longitudinal and transversal steel rebar details
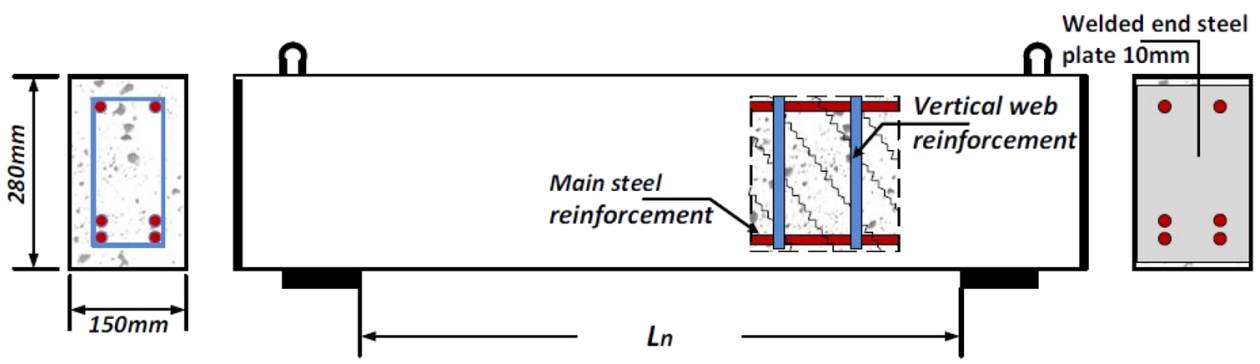

Table 2 Concrete mixture quantities (by weight), $\mathrm{kg} / \mathrm{m}^{3}$

\begin{tabular}{lllll}
\hline Water $(\mathrm{kg})$ & $\begin{array}{l}\text { Coarse } \\
\text { aggregate } \\
(\mathrm{kg})\end{array}$ & $\begin{array}{l}\text { Fine aggre- } \\
\text { g1ate }(\mathrm{kg})\end{array}$ & $\begin{array}{l}\text { Portland } \\
\text { cement }(\mathrm{kg})\end{array}$ & $\begin{array}{l}\text { Water// } \\
\text { cement ratio }\end{array}$ \\
\hline 165 & 1,134 & 756 & 400 & 0.4 \\
\hline
\end{tabular}

nearby concrete surface during loading [8]. According to the aforementioned fact, partial debonding of the CFRP layer was observed primarily in the failure of shear for RCDBs with CFRP. For all deep beam specimens strengthened with CFRP sheets having $45^{\circ}$ and $90^{\circ}$ fiber directions and different CFRP schemes, typical shear failure with CFRP debonding occurs. Figure 7 displays the characteristic of failure mode exhibited in this experimental program for RCDBs reinforced by CFRP laminates. Figure 7 also illustrates that the combination of the shear in the concrete and CFRP debonding failure modes typically happened with partial CFRP shear debonding. Likewise, in terms of unstrengthen deep beam, the cracks of diagonal shear propagated toward the loading and support plates. The results showed that the tensile strain of the CFRP layer also increased as the breadth of the splits developed. Besides, sections of the beam segment without CFRP layer delamination failed in shear.

In conclusion, the CFRP sheet debonding failure was primarily controlled by the mode of failure of RCDBs reinforced by CFRP on both sides. This is occurred, according to the experimental observations, due to the connection between concrete and fiber began to split at a specific amount of load. Besides, the failure was separated into

Table 3 The characteristics of CFRP sheets and epoxy

\begin{tabular}{|c|c|c|c|c|c|}
\hline Material & & $\begin{array}{l}\text { Tensile modulus of } \\
\text { elasticity, } \mathrm{GPa}\end{array}$ & $\begin{array}{l}\text { Tensile } \\
\text { strength, MPa }\end{array}$ & $\begin{array}{l}\text { Rupture strain } \\
\text { (Ultimate) }\end{array}$ & $\begin{array}{l}\text { Thickness } \\
\text { (mm/ply) }\end{array}$ \\
\hline Epoxy (provided by the producer) & & 3.034 & 54 & $3.5 \%$ & - \\
\hline \multirow[t]{2}{*}{ CFRP layer } & Provided by the producer & 227 & 3800 & $1.67 \%$ & 0.166 \\
\hline & Experimentally (average) & 226.59 & 3153.56 & $1.34 \%$ & 0.166 \\
\hline
\end{tabular}

Fig. 5 Schematic of the test setup

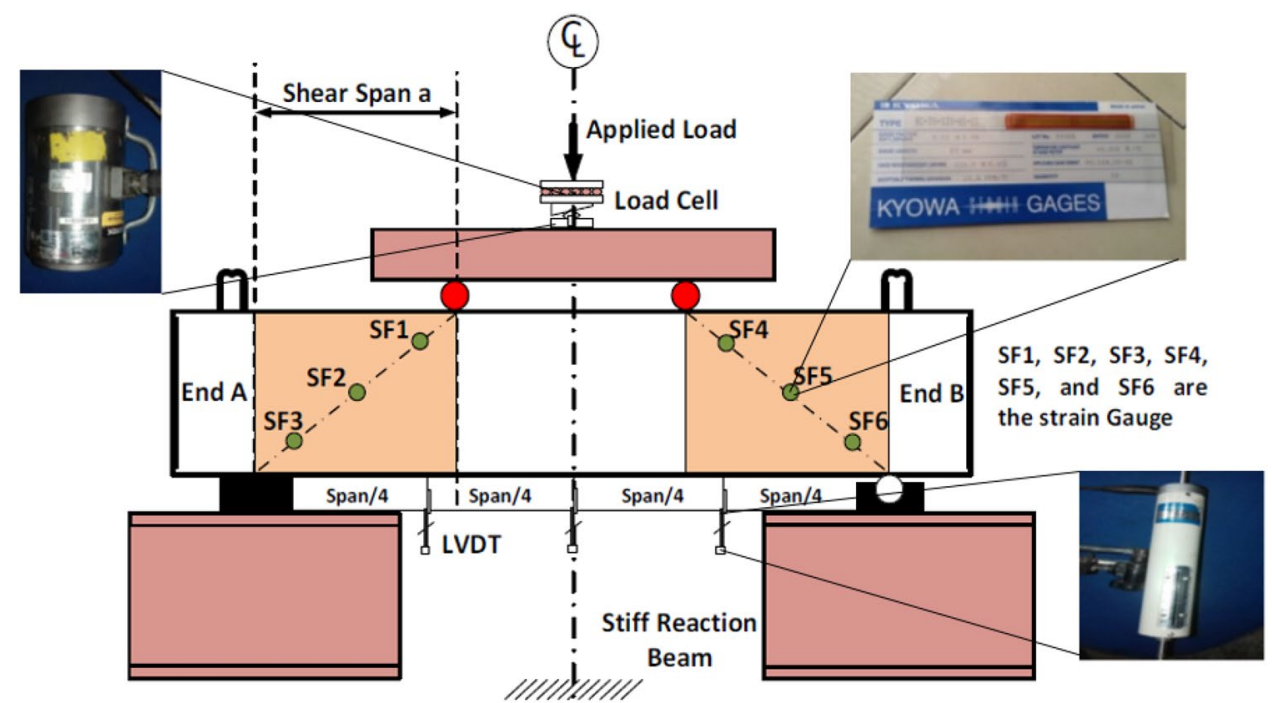



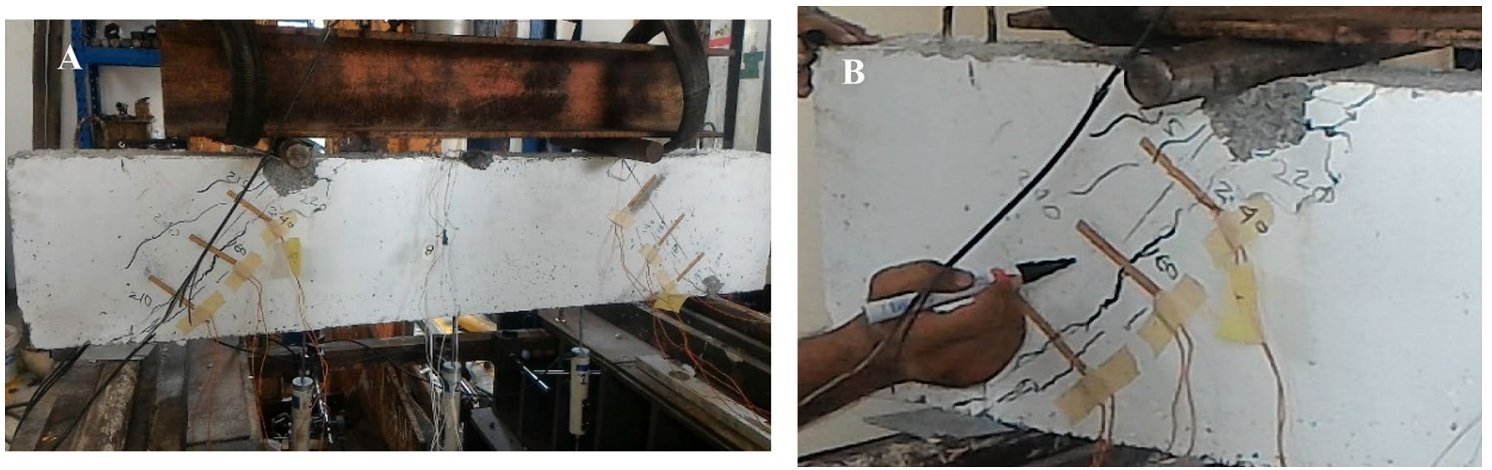

Fig. 6 Shear failure mode and crack patterns of conventional tested RCDB a overall view b close-up view

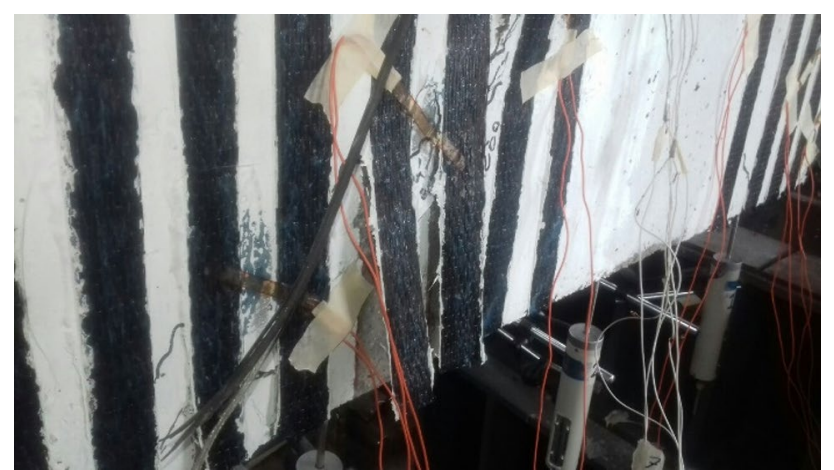

Fig. 7 Failure connection of fibers for RCDBs with CFRP

the shear region until the propagation of the fiber from the concrete samples. Moreover, under the applied load, the first diagonal cracks performed started at the inclination of the $a_{v} / d$.

\subsection{Crack pattern and propagation}

. Crack width is considered as one of the major study factors to evaluate the serviceability of RC architectural components. It was observed during the experimental work conducted on RCDBs, that the elastic behavior controlled about $30 \%$ of the ultimate shear strength load $(P u)$ in the first phases of load increments. After that, the diagonal cracks were initially performed in the mid-span of beam sections and therefore stretched into the support and load zones. The increase in load resulted in a further rise in the widening and extension of current cracks. at the same time, new diagonal cracks were performed. It is worth mentioning that the implemented load was 50\% higher than the ultimate load. During the applied load, the flexural cracks propagated and elongated slightly to the center of RCDB samples. Eventually, one of the diagonal

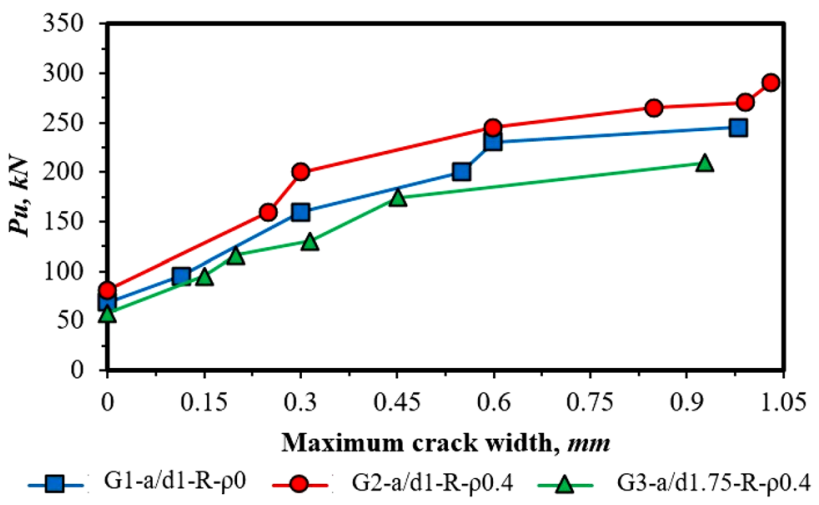

Fig. 8 Oblique crack width values for unstrengthen RCDBs

cracks noticeably stretched and expanded at around 90\% of the $P_{u}$ and followed by the beams' final collapse.

The maximum diagonal cracks width of conventional RCDBs and the related loads were determined to up around $90 \%$ of the $P u$. Figure 8 shows that the applied load associated with the first inclined cracks initially decreased as the $a_{v} / d$ proportion increased. In addition, a marginally measured rise in the final maximum width of inclined cracks was observed in this experiment during the growth in $a_{v} / d$ proportion. In RCDBs members reinforced by CFRP, these cracks are hindered because the CFRP has a bridge performance in transferring loads over the cracks. Thus, more energy is required and this drives to increase the absorbed energy in the tested beams [24]. Nevertheless, it was impossible to measure the inclining crack widths of $\mathrm{RCDBs}$ reinforced by the CFRP layer because those cracks were covered by the CFRP coupon.

\subsection{Load-deflection relationship}

The load verification for the experimented hybrid RCDBs is conducted theoretically by Strut-and-Tie (STM) method (Eq. 3) using Mohr-Columb assumption and 
also numerically by particle swarm optimization algorithm (PSO) using MATLAB software to optimize the suggested STM as shown in Table 4. In this table, the $P_{\text {u-Exp.' }}$ $P_{\mathrm{U}-\mathrm{STM}}$, and $P_{\mathrm{U}-\mathrm{PSO}}$ represent the ultimate shear strength of the hybrid strengthen RCDBs from the current experiment, STM, and from the PSO respectively. The major purpose of using the PSO algorithm is to optimize the best value of the reduction coefficients of concrete tensile $(\lambda)$. The details and discussions regarding the derivation, verification, validation, and error evaluation methods can be found elsewhere by Hanoon et al. [10].

$V_{n}=\frac{1}{\frac{\operatorname{Sin}_{2 \theta_{s}}}{f_{t} A_{c}}+\frac{\lambda}{A_{s t}{ }^{\prime} \operatorname{Sin}_{c} \operatorname{Si}_{\vartheta_{S}}}}$

where $V_{n}, \vartheta_{s}, f_{t}, A_{c}, \lambda, A_{s t r}$, and $f_{c}^{\prime}$ are the nominal shear strength, strut angle, reinforcement tensile strength, cross-sectional area of the deep beam, a reduction factor of concrete tensile, strut cross-sectional area, and concrete compressive strength respectively.

It was perceptibly observed during experimentation that when the $a / d$ ratio decreased, the brittle failure clearly increased in RCDB without CFRP. On the contrary, brittle failure action was obviously to be lower with hybrid CFRP beams. Table 4 indicates that once the ratio of $a_{v} / d$ increases, the deflection of mid-span increases related to the $P u$ for the RCDBs with and without CFRP. Concerning hybrid beams with CFRP, the mid-span deflection and applied loads were recorded during the experiment. The presence of various CFRP sheet arrangements resulted in an improvement in the ultimate shear strength capability of the experimented hybrid RC deep beam reinforced by CFRP as expressed in Fig. 9.

\subsection{Deformability factor and ductility energy index (energy ratio)}

To assess the influences of the experimental configuration factors on the post-peak deformability and ductility energy index of the all tested RCDBs, both of the deformability and ductility energy indices were employed.

During considering the hybrid RC beams with FRP, the deformability factor becomes more significant than ductility $[25,26]$. The deformability factor $(\lambda)$ is defined as the ratio of the displacement at the ultimate load to the displacement at maximum load (Eq. 6) as shown in Table 5 Fig. 10. The ultimate load is equal to the load related to $85 \%$ of the maximum load on the decreasing part of the load-deflection curve [27]. The equation can be formulated as:

$\lambda=\frac{\Delta_{f}}{\Delta_{\max }}$

where $\Delta_{f}$ is the displacement at failure load, and $\Delta_{\max }$ is the displacement at maximum load (Fig. 10). It can be seen from Table 5 that the deformability factor is increased with the attendance of $0.4 \%$ shear steel ratio, lower shear span to depth ratio (1.0), and CFRP sheets. On the other hand, the $\lambda$ is recorded as the lowest value with the absence of the mentioned factors.

In a concrete component, the transfer from mechanical energy to the inherent possible energy is referred to by the absorbed energy. The absorbed energy of concrete components involves a variety of composite processes, comprising plastic and elastic deformation in addition to the rupture mechanics of crack propagation and initiation. Ductility of the sample is required to maintain any sudden overloading situations.

For all beams, the absorbed energy, which represented the region beneath the load-deflection curve $(P-\Delta)$, was
Table 4 Applied load details of the hybrid tested RCDBs

\begin{tabular}{|c|c|c|c|c|c|c|}
\hline Beam & $\Delta_{\max }$ & $P_{\mathrm{u}-\mathrm{Exp} .,} \mathrm{kN}$ & $P_{\mathrm{u}-\mathrm{PSO}}, \mathrm{kN}$ & $P_{\mathrm{u}-\mathrm{STM}}, \mathrm{kN}$ & $P_{\mathrm{u}-\mathrm{Exp} . .} / P_{\mathrm{u}-\mathrm{PSO}}$ & $P_{\mathrm{u}-\mathrm{Exp}} / P_{\mathrm{u}-\mathrm{STM}}$ \\
\hline $\mathrm{G} 1-a / d 1-\mathrm{F}-\rho 0$ & 11.58 & 325.51 & 333.65 & 368.12 & 0.976 & 0.884 \\
\hline $\mathrm{G} 1-a / d 1-P 90^{\circ}-\rho 0$ & 10.67 & 276.25 & 320.53 & 352.1 & 0.862 & 0.785 \\
\hline $\mathrm{G} 1-a / d 1-\mathrm{P} 45^{\circ}-\rho 0$ & 10.81 & 291.29 & 328.60 & 361.69 & 0.886 & 0.805 \\
\hline $\mathrm{G} 2-a / d 1-\mathrm{F}-\rho 0.4$ & 8.55 & 343.40 & 338.44 & 373.91 & 1.015 & 0.918 \\
\hline $\mathrm{G} 2-a / d 1-\mathrm{P} 90^{\circ}-\rho 0.4$ & 8.07 & 320.23 & 326.49 & 359.25 & 0.981 & 0.891 \\
\hline $\mathrm{G} 2-a / d 1-\mathrm{P} 45^{\circ}-\rho 0.4$ & 9.84 & 335.29 & 333.80 & 367.98 & 1.004 & 0.911 \\
\hline G3-a/d1.75-F-p0.4 & 8.71 & 255.18 & 277.51 & 307.82 & 0.920 & 0.829 \\
\hline G3-a/d1.75-P90-p0.4 & 11.43 & 290.02 & 264.38 & 292.1 & 1.097 & 0.993 \\
\hline 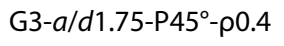 & 10.89 & 278.08 & 265.56 & 293.28 & 1.047 & 0.948 \\
\hline Mean & & & & & 0.976 & 0.885 \\
\hline SD & & & & & 0.076 & 0.068 \\
\hline $\mathrm{CoV}$ & & & & & $7.79 \%$ & $7.69 \%$ \\
\hline
\end{tabular}



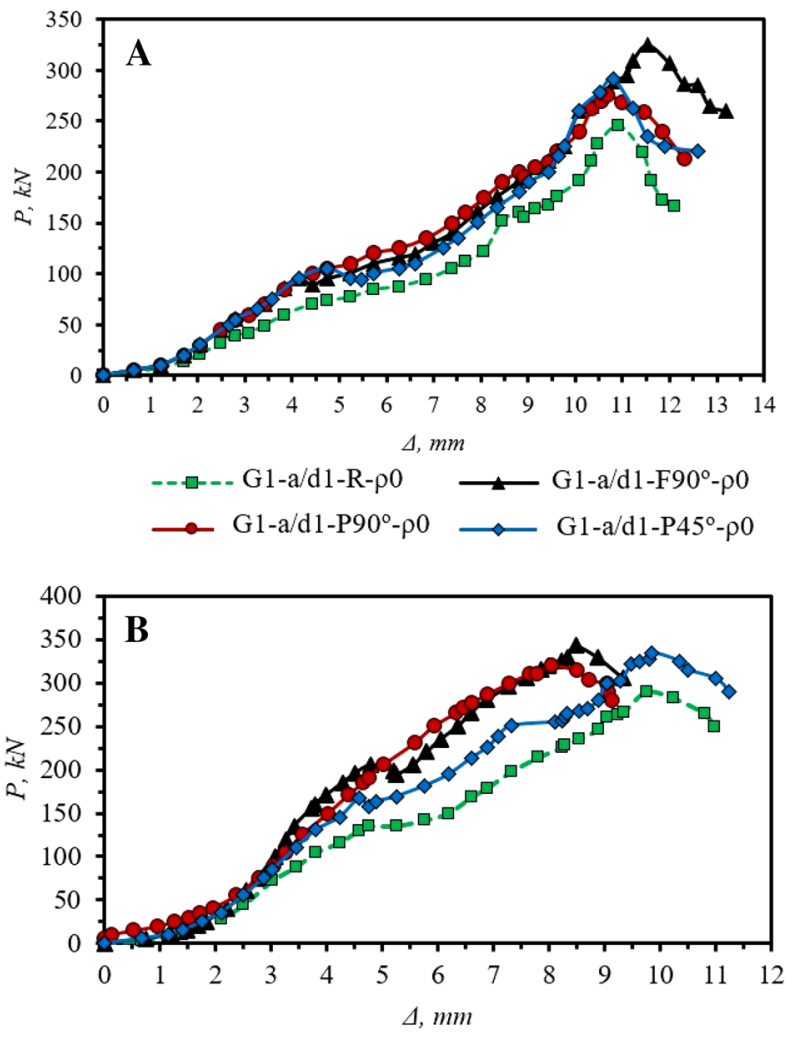

$\rightarrow-\square-\mathrm{G} 2-\mathrm{a} / \mathrm{d} 1-\mathrm{R}-\mathrm{p} 0.4 \longrightarrow \mathrm{G} 2-\mathrm{a} / \mathrm{d} 1-\mathrm{F} 90^{\circ}-\mathrm{p} 0.4$

$\longrightarrow$ G2-a/d1-P90 $-\rho 0.4 \longrightarrow$ G2-a/d1-P45 00.4

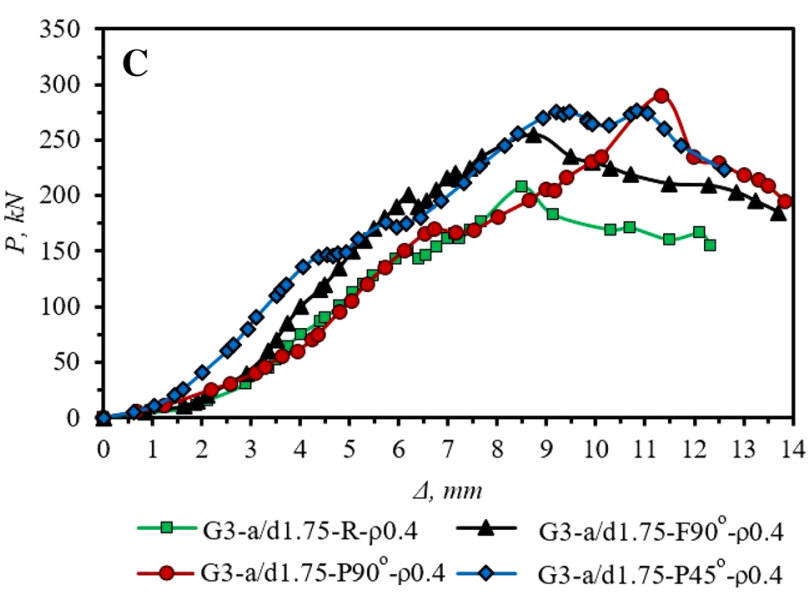

Fig. 9 Relationship between load vs deflection of a Group $1 \mathbf{b}$ Group 2, c Group 3 determined using Simpson's law [15]. In this study, Spadea et al. [22] technique (Eq. 5 and Fig. 10) is adopted to determine the ductility energy index $\left(\mu_{E}\right)$ for the hybrid FRP$\mathrm{RC}$ deep beams, which is equal to total energy under the load-deflection curve up to the failure load $\left(E_{\text {tot }}\right)$, to the energy under the curve up to $75 \%$ of the maximum load $\left(E_{@ 75 \% P \text { max }}\right)$ as shown in Table 5 and Fig. 10. The maximum increment in the $\mu_{E}$-index is about $38.26 \%, 61.31 \%$, and 51.42 for beams (G1-a/d1-F- 00$),\left(\mathrm{G} 2-a / d 1-\mathrm{P} 90^{\circ}-\rho 0.4\right)$, and (G3- $a / d 1.75-\mathrm{F}-\rho 0.4)$ respectively relative to their reference beams. It is worth mentioning that the energy ratio of the reference beam in group 3 is higher than the energy ratio of beams with $45^{\circ}$ and $90^{\circ} \mathrm{CFRP}$ stripes due to maybe earlier debonding failure of CFRP or technical setup during implementation.

The energy dissipated by the member before the collapse is utilized as a determination of the ductility. According to Fig. 11, the energy absorption capacity is marginally higher in hybrid CFRP beams relative to those of traditional RCDBs. The increment of absorbed energy fluctuates from about $15 \%$ to $51 \%$ for $a_{v} / d$ values of 1.0 and 1.75 respectively, and for reinforcement percentages of $0 \%$ to $0.4 \%$ from about $15 \%$ to $86 \%$ consecutively. According to the experimental observations, CFRP layers led to growth in the ultimate shear measurements and energy absorption of the retrofit $\mathrm{RC}$ samples relative to the reference.

A reliable positive relationship between ductility and energy absorption capacity of the concrete component has been shown by numerous studies. The bar chart in Fig. 12a and $b$ express the comparison of the ductility energy ratio $\left(\mu_{E}\right)$ of the hybrid RCDBs samples in terms of vertical reinforcement ratio and shear span to depth ratio, respectively. The $\mu_{E}$ developed with the attendance of CFRP layers. The strip warped of $45^{\circ}$ and $90^{\circ}$ aligned CFRP sheets increased the load-deflection region beneath the curve of the control sample. The maximum energy ratio is about 2.75 for the beam (G2- $a / d$ 1-P90- $\rho 0.4$ ) as shown in Fig. $12 \mathrm{a}$, whereas, the maximum energy ratio is about 4.93 for the beam (G3-a/d 1.75-F- $\rho$ 0.4) as shown in Fig. 12b. 
Table 5 Deformability factor and ductility energy index of the tested RCDBs

\begin{tabular}{|c|c|c|c|c|c|c|c|c|c|}
\hline \multirow[t]{2}{*}{ Group } & \multirow[t]{2}{*}{ Beam ID } & \multicolumn{2}{|c|}{ Load, kN } & \multicolumn{2}{|c|}{ Displacement, mm } & \multirow[t]{2}{*}{$\lambda$} & \multirow[t]{2}{*}{$E_{\text {tot }}, \mathrm{kN} \cdot \mathrm{mm}$} & \multirow[t]{2}{*}{$E_{@ 0.75 P \max }, \mathrm{kN} \cdot \mathrm{mm}$} & \multirow[t]{2}{*}{$\mu_{E}$} \\
\hline & & $P_{\max }$ & $P_{f}$ & $\Delta_{\max }$ & $\Delta_{f}$ & & & & \\
\hline \multirow[t]{4}{*}{ Group 1} & $\mathrm{G} 1-a / d 1-\mathrm{R}-\rho 0$ & 245.20 & 208.42 & 10.88 & 11.65 & 1.07 & 1209.76 & 757.59 & 1.60 \\
\hline & $\mathrm{G} 1-a / d 1-\mathrm{F}-\rho 0$ & 325.51 & 276.68 & 11.58 & 12.75 & 1.10 & 2256.16 & 1021.93 & 2.21 \\
\hline & $\mathrm{G} 1-a / d 1-\mathrm{P} 90^{\circ}-\rho 0$ & 276.25 & 234.81 & 10.67 & 11.97 & 1.12 & 1925.37 & 903.87 & 2.13 \\
\hline & $\mathrm{G} 1-a / d 1-\mathrm{P} 45^{\circ}-\rho 0$ & 291.29 & 247.60 & 10.81 & 11.35 & 1.05 & 1616.3 & 903.37 & 1.79 \\
\hline \multirow[t]{4}{*}{ Group 2} & $\mathrm{G} 2-a / d$ 1-R-p0.4 & 290.87 & 247.24 & 9.75 & 11 & 1.13 & 1361.18 & 797.92 & 1.71 \\
\hline & $\mathrm{G} 2-a / d$ 1-F- $\rho 0.4$ & 343.40 & 291.89 & 8.55 & 9.93 & 1.16 & 1562.73 & 723.85 & 2.16 \\
\hline & $\mathrm{G} 2-a / d$ 1-P $90^{\circ}-\rho 0.4$ & 320.23 & 272.20 & 8.07 & 9.21 & 1.14 & 1616.82 & 587.56 & 2.75 \\
\hline & $\mathrm{G} 2-a / d 1-\mathrm{P} 45^{\circ}-\rho 0.4$ & 335.29 & 285.00 & 9.84 & 11.22 & 1.14 & 1952.94 & 790.56 & 2.47 \\
\hline \multirow[t]{4}{*}{ Group 3} & G3-a/d 1.75-R-p0.4 & 208.06 & 176.85 & 8.51 & 9.41 & 1.11 & 1389.36 & 426.38 & 3.26 \\
\hline & $\mathrm{G} 3-a / d$ 1.75-F-p0.4 & 255.18 & 216.90 & 8.71 & 10.91 & 1.25 & 1978.75 & 401.05 & 4.93 \\
\hline & $\mathrm{G} 3-a / d 1.75-\mathrm{P} 90^{\circ}-\rho 0.4$ & 290.02 & 246.51 & 11.43 & 11.91 & 1.04 & 2093.51 & 935.16 & 2.24 \\
\hline & 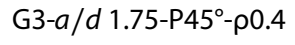 & 278.08 & 236.37 & 10.89 & 12.15 & 1.12 & 2104.56 & 733.88 & 2.87 \\
\hline
\end{tabular}

\section{Conclusions}

The current paper displays the results of an experimental examination of the twelve RC deep beams strengthen by various configurations of transverse (shear) CFRP sheets (full side warped, $90^{\circ}$ and $45^{\circ}$ side strips) against shear strength load. A refined strategy of the Spadea ductility index is adopted to measure the RCDBs ductility by the mean of the toughness (energy absorption) with two values of $a / d$ ratios (1.0 and 1.75) and shear reinforcement ratios ( $0 \%$ and $0.4 \%$ ). The tested beams were divided into three groups according to the CFRP configurations, $a / d$, and $\rho_{v}$.

The results show that once the $a / d$ ratio increased, energy absorption decreased for both conventional and hybrid RCDBs. The amount of dissipated energy displayed by CFRP beams is from 45 to $80 \%$ and it is higher than those of conventional beam. Approximately a linear relationship is the growth correlation of dissipated energy with $a / d$ ratio. The ultimate shear strength reduced and the deflection of mid-span growth with the increasing of $a / d$ percentage for strengthen and unstrengthen RCDBs. Particularly, CFRP beams exhibit a higher rate of growth in terms of mid-span deflection relative to ordinary RCDBs. Experimental findings are expressed that the shear strength was increased per CFRP addition. This pattern illustrates the improvement of the practical strength of the strut resulting from the enhancing of the CFRP, which can control crack expanding to contribute as a finding from this research. The ductility performance was improved for RCDB reinforced by the CFRP layer relative to control RCDBs. The ductility energy index $\left(\mu_{E}\right)$ is improved with the presence of CFRP layers. The $45^{\circ}$ and $90^{\circ}$ CFRP stripes are increased the load-deflection area below the curve for the tested sample.

Numerous utilizations may worth more analytical study for ductility energy modeling of hybrid RCDB reinforced with CFRP sheets, as well as investigation of unloading branches in deflection-load curves to assess structural energy absorption. Besides, a further examination concerning beams, slabs, and walls with opening need to be studied, in terms of ductility and energy absorption, with a new experiment, numerical and theoretical tests. 

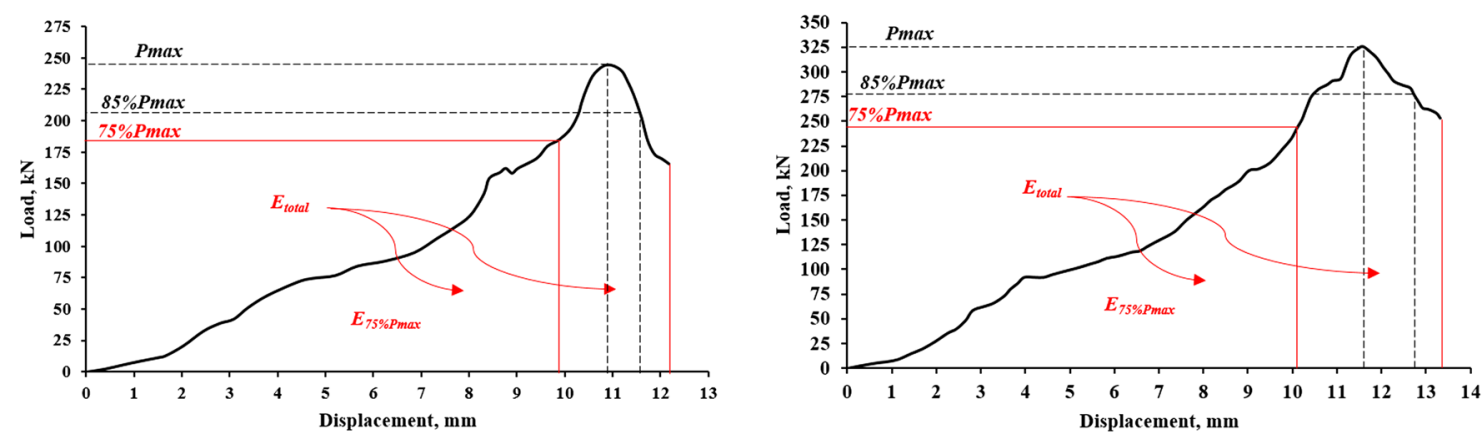

G1- $a / d 1-\mathrm{R}-\rho 0$

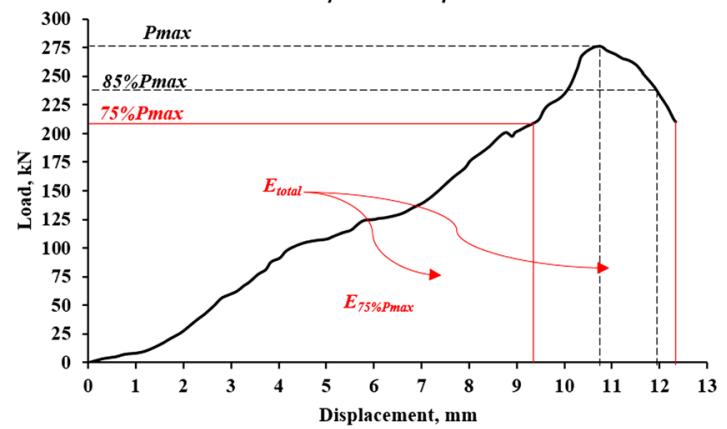

$\mathrm{G} 1-a / d 1-\mathrm{P}^{\circ} 0^{\circ}-\rho 0$
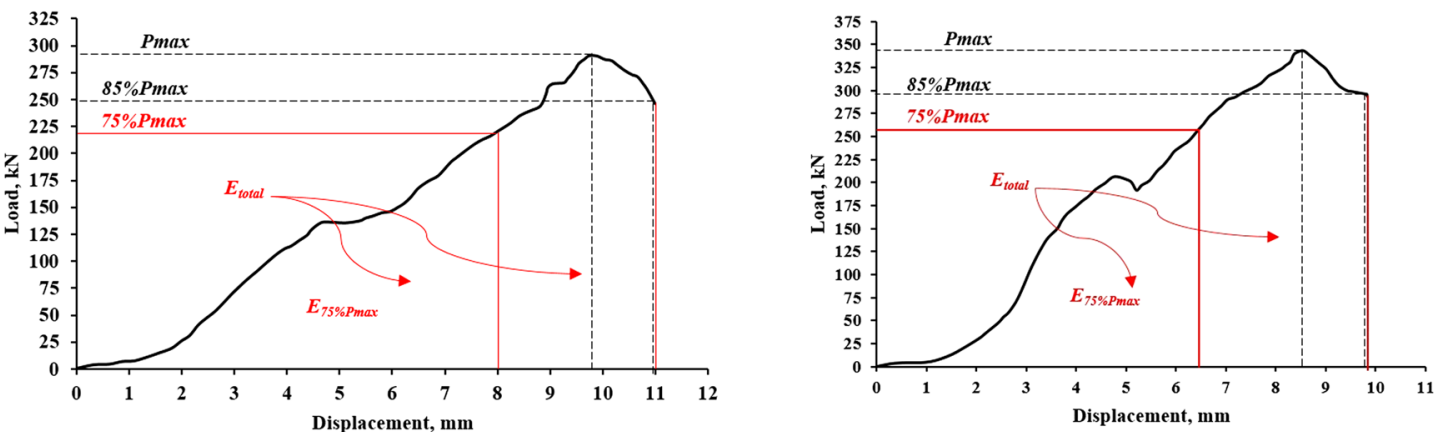

G2- $a / d 1-\mathrm{R}-\rho 0.4$

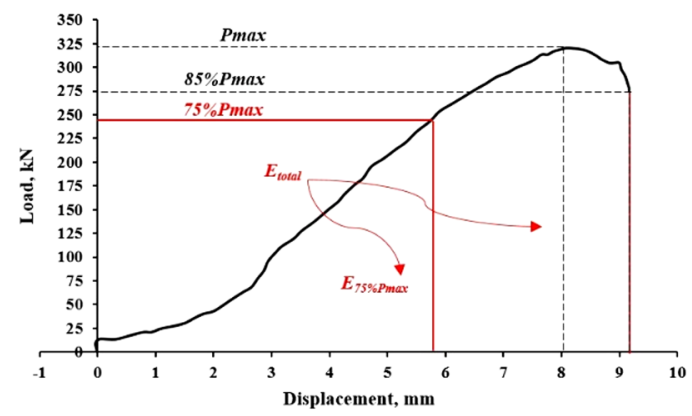

$\mathrm{G} 2-a / d 1-\mathrm{P}^{\circ} 0^{\circ}-\rho 0.4$

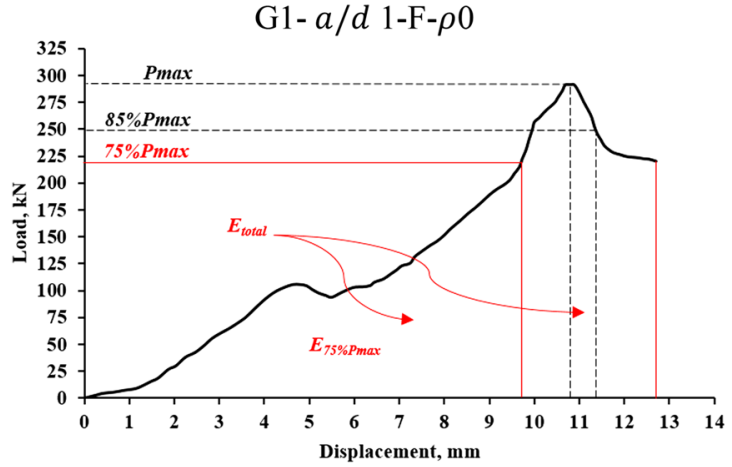

$\mathrm{G} 1-a / d \mathrm{~d} 1-\mathrm{P} 90^{\circ}-\rho 0$

G2- $a / d 1-\mathrm{F}-\rho 0.4$

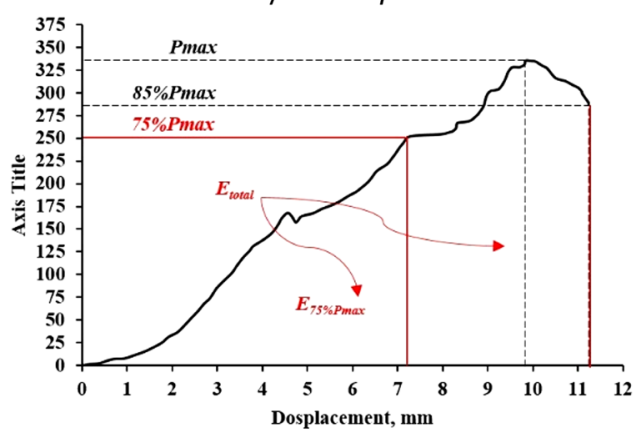

$\mathrm{G} 2-a / d 1-\mathrm{P} 45^{\circ}-\rho 0.4$

Fig. 10 Deformability and energy ratio indices calculation method 


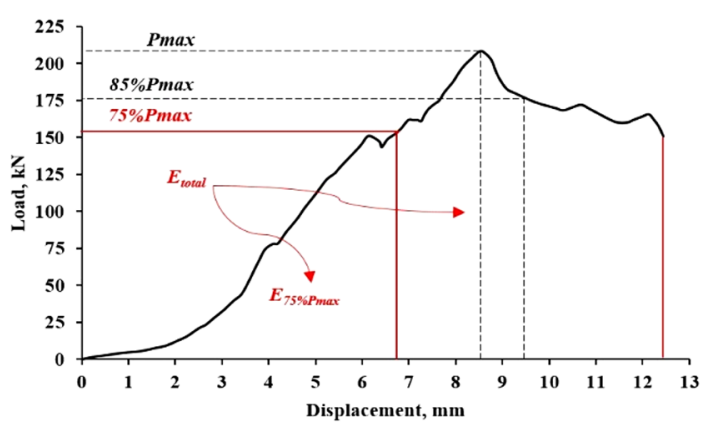

G3- $a / d 1.75-\mathrm{R}-\rho 0.4$

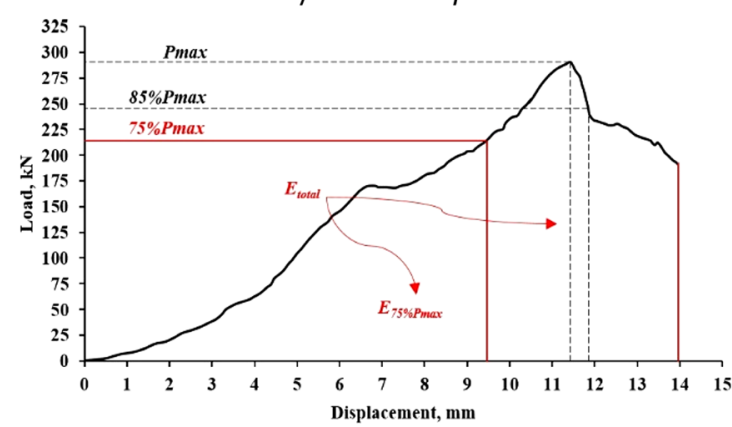

$\mathrm{G} 3-a / d 1.75-\mathrm{P} 90^{\circ}-\rho 0.4$

Fig. 10 (continued)

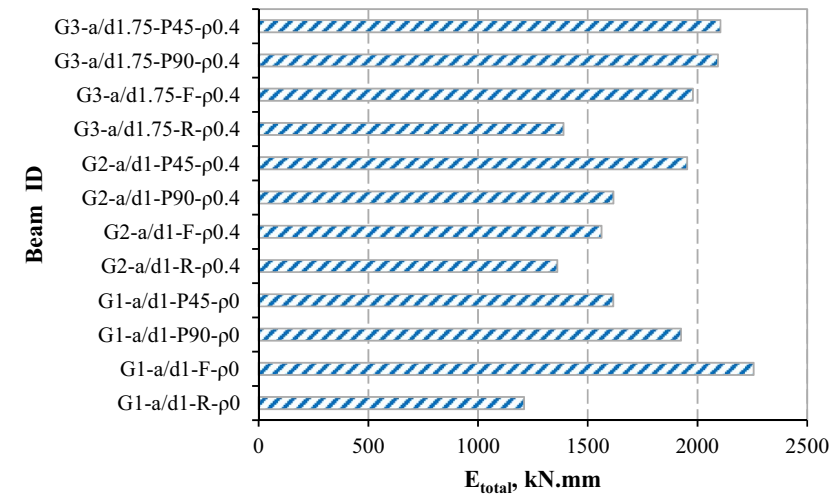

Fig. 11 Capacity of absorbed energy of the tested RCDBs

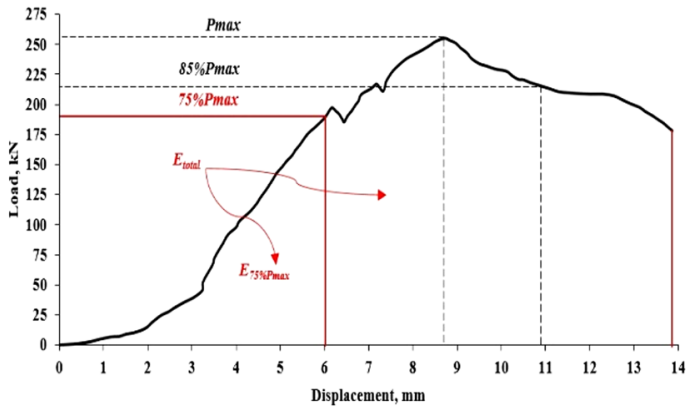

G3- $a / d$ 1.75-F- $\rho 0.4$

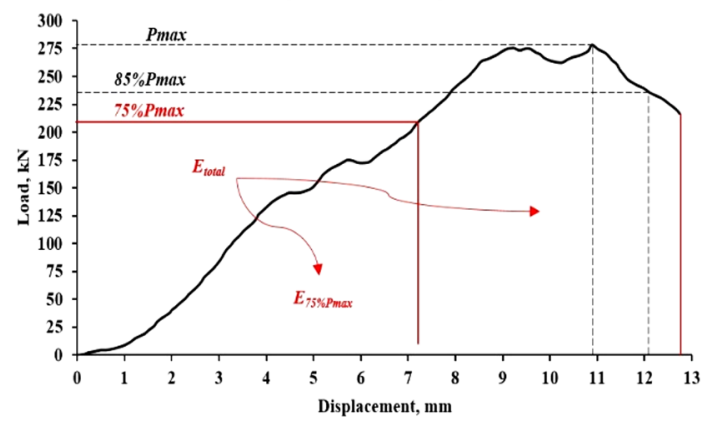

$\mathrm{G} 3-a / d 1.75-\mathrm{P} 45^{\circ}-\rho 0.4$
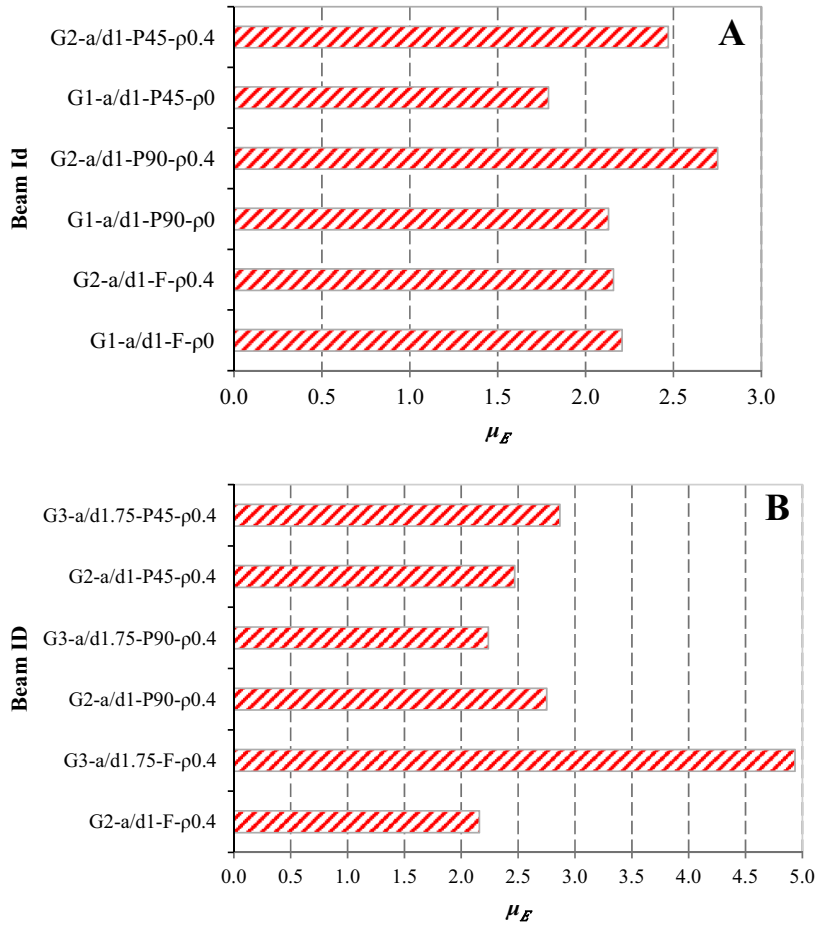

Fig. 12 Effect of $\rho_{v}$ and $a / d$ proportions, on energy ductility ratio $\left(\mu_{E}\right)$ of hybrid RCDBs reinforced by CFRP a Shear reinforcement ratio $\left(\rho_{v}\right)$, b Shear span to depth ratio $(a / d)$ 
Acknowledgements The authors would like to express their gratitude for the support provided by Universiti Putra Malaysia (UPM)

\section{Compliance with ethical standards}

Conflict of interest The authors affirm that no conflict of interest.

Open Access This article is licensed under a Creative Commons Attribution 4.0 International License, which permits use, sharing, adaptation, distribution and reproduction in any medium or format, as long as you give appropriate credit to the original author(s) and the source, provide a link to the Creative Commons licence, and indicate if changes were made. The images or other third party material in this article are included in the article's Creative Commons licence, unless indicated otherwise in a credit line to the material. If material is not included in the article's Creative Commons licence and your intended use is not permitted by statutory regulation or exceeds the permitted use, you will need to obtain permission directly from the copyright holder. To view a copy of this licence, visit http://creativecommons. org/licenses/by/4.0/.

\section{References}

1. Zhang N, Tan K-H (2007) Direct strut-and-tie model for singlespan and continuous deep beams. Eng Struct 29(11):2987-3001. https://doi.org/10.1016/j.engstruct.2007.02.004

2. Committee $A A C l$ (2014) Building code requirements for structural concrete ( $\mathrm{ACl} 318 \mathrm{M}-14)$ : An $\mathrm{ACl}$ standard: commentary on building code requirements for structural concrete $(\mathrm{ACl}$ 318M-14). American Concrete Institute, Farmington Hills, MI

3. Mahmod M, Hanoon AN, Abed HJ (2018) Flexural behavior of self-compacting concrete beams strengthened with steel fiber reinforcement. J Build Eng 16:228-237. https://doi. org/10.1016/j.jobe.2018.01.006

4. Jabbar S, Hejazi F, Mahmod HM (2016) Effect of an opening on reinforced concrete hollow beam web under torsional, flexural, and cyclic loadings. Latin Am J Solids Struct 13(8):1576-1595. https://doi.org/10.1590/1679-782512629

5. Sardar S, Mahmod M, Shakir I (2017) Nonlinear pushover analysis for steel beam-column connection. Eur J Sci Eng 3(1):83-98. https://doi.org/10.23918/eajse.v3i1sip83

6. Danraka MN, Mahmod HM, Oluwatosin O-KJ, Student P (2017) Strengthening of reinforced concrete beams using FRP technique: a review. Int J Eng Sci 7(6):13199

7. Mahmod HM, Aznieta AFN, Gatea SJ (2017) Evaluation of rubberized fiber mortar exposed to elevated temperature using destructive and non-destructive testing. KSCE J Civ Eng 21(4):1347-1358. https://doi.org/10.1007/s12205-016-0721-0

8. Naser MZ, Hawileh RA, Abdalla JA (2019) Fiber-reinforced polymer composites in strengthening reinforced concrete structures: a critical review. Eng Struct 198:109542. https://doi. org/10.1016/j.engstruct.2019.109542

9. Hanoon AN, Jaafar M, Hejazi F, Abdul Aziz FN (2017) Energy absorption evaluation of reinforced concrete beams under various loading rates based on particle swarm optimization technique. Eng Optim 49(9):1483-1501. https://doi. org/10.1080/0305215x.2016.1256729

10. Hanoon AN, Jaafar M, Hejazi F, Aziz FNA (2017) Strut-and-tie model for externally bonded CFRP-strengthened reinforced concrete deep beams based on particle swarm optimization algorithm: CFRP debonding and rupture. Constr Build Mater 147:428-447. https://doi.org/10.1016/j.conbuildma t.2017.04.094
11. Saqan El, Rasheed HA, Hawileh RA (2013) An efficient design procedure for flexural strengthening of $\mathrm{RC}$ beams based on $\mathrm{ACl}$ 440.2R-08. Compos B Eng 49:71-79. https://doi.org/10.1016/j. compositesb.2013.01.006

12. Barrera A, Bonet J, Romero ML, Fernández M (2012) Ductility of slender reinforced concrete columns under monotonic flexure and constant axial load. Eng Struct 40:398-412. https://doi. org/10.1016/j.engstruct.2012.03.012

13. Hason MM, Hanoon AN, Al Zand AW, Abdulhameed AA, AlSulttani AO (2020) Torsional strengthening of reinforced concrete beams with externally-bonded fibre reinforced polymer: an energy absorption evaluation. Civ Eng J 6(Special issue “Emerging Materials in Civil Engineering"):69-85. https://doi. org/10.28991/cej-2020-SP(EMCE)-07

14. Hanoon AN, Abdulhameed AA, Abdulhameed HA, Mohaisen SK (2019) Energy absorption evaluation of CFRP-strengthened two-spans reinforced concrete beams under pure torsion. Civ Eng J. https://doi.org/10.28991/cej-2019-03091389

15. Hu Y, Shi Y, Liu D, Guo J, Zhang J, Chen Z (2020) Damage tolerance of 2-dimensional UHMWPE/CF hybrid woven laminates subjected to low-velocity impact. Mater Des 191:108604. https ://doi.org/10.1016/j.matdes.2020.108604

16. Anvari A, Ghalehnovi M, de Brito J, Karimipour A (2020) Improved bending behavior of steel-fiber-reinforced recycled aggregate concrete beams with a concrete jacket. Mag Concr Res. https://doi.org/10.1680/jmacr.19.00146

17. Chaboki HR, Ghalehnovi M, Karimipour A, de Brito J, Khatibinia M (2019) Shear behavior of concrete beams with recycled aggregate and steel fibers. Constr Build Mater 204:809-827. https:// doi.org/10.1016/j.conbuildmat.2019.01.130

18. Chaboki HR, Ghalehnovi M, Karimipour A, de Brito J (2018) Experimental study on the flexural behavior and ductility ratio of steel fibers coarse recycled aggregate concrete beams. Constr Build Mater 186:400-422. https://doi.org/10.1016/j.conbuildma t.2018.07.132

19. Erki M, Meier U (1999) Impact loading of concrete beams externally strengthened with CFRP laminates. J Compos Constr 3(3):117-124. https://doi.org/10.1061/ (ASCE) 1090-0268(1999)3:3(117)

20. Mohamed HM, Masmoudi R (2010) Flexural strength and behavior of steel and FRP-reinforced concrete-filled FRP tube beams. Eng Struct 32(11):3789-3800. https://doi.org/10.1016/j.engst ruct.2010.08.023

21. Panjehpour M, Abang AAA, Aznieta FN (2014) Energy absorption of reinforced concrete deep beams strengthened with CFRP sheet. Steel Compos Struct 16(5):481-489. https://doi. org/10.12989/scs.2014.16.5.481

22. Spadea G, Bencardino F, Swamy R (1997) Strengthening and upgrading structures with bonded CFRP sheets design aspects for structural integrity. In: Proceedings of 3rd International Symposium on Non-Metallic (FRP) Reinforcement for Concrete Structures

23. Knight $M$, Thomson N (2001) Underground infrastructure research. CRC Press, Boca Raton

24. Ghalehnovi M, Karimipour A, de Brito J (2019) Influence of steel fibers on the flexural performance of reinforced concrete beams with lap-spliced bars. Constr Build Mater 229:116853. https:// doi.org/10.1016/j.conbuildmat.2019.116853

25. Alsayed SH, Alhozaimy AM (1999) Ductility of concrete beams reinforced with FRP bars and steel fibers. J Compos Mater 33(19):1792-1806. https://doi.org/10.1177/002199839903301 902

26. Jaejer L, Mufti A, Tadros G (1997) The concept of the overall performance factor in rectangular-section reinforced concrete beams. In: Proceedings of the 3rd international symposium on non-metallic (FRP) reinforcement for concrete structures 
27. Mussa MH, Abdulhadi AM, Abbood IS, Mutalib AA, Yaseen ZM (2020) Late age dynamic strength of high-volume fly ash concrete with nano-silica and polypropylene fibres. Crystals 10(4):243. https://doi.org/10.3390/cryst10040243
Publisher's Note Springer Nature remains neutral with regard to jurisdictional claims in published maps and institutional affiliations. 